\title{
Finanzen im Spital
}

Für den Nicht-Finanzexperten sind Interpretation und Anwendung von finanzrelevanten Daten oft schwierig, zur effizienten Klinikführung sind sie heute jedoch unerlässlich. Die Einführung von DRGs verunsichert und verwirrt zusätzlich; erste Erfahrungen zeigen, dass sie den Klinikbetrieb massgeblich beeinflussen.

Ziel dieses Kurses ist es, Kenntnisse der Grundlagen im Finanzwesen zu vermitteln, das Verständnis der Zusammenhänge im Finanzwesen zu fördern und erste Auswirkungen der DRGs auf den Spitalalltag aufzuzeigen. Der Kurs soll Ärztinnen und Ärzten in leitender Stellung helfen, ihre Anliegen effizient vorzubringen und durchzusetzen. Sie werden dadurch ernstzunehmende Gesprächspartner auf Führungsebene. Grosser Raum wird der Diskussion mit praxiserfahrenen Experten sowie dem offenen Erfahrungsaustausch unter den Teilnehmenden beigemessen.

\section{Kursinhalt}

- Einführung in die Bilanz, Erfolgsrechnung und das betriebliche Rechnungswesen (Kostenstellenrechnung, Prozesskostenrechnung usw.);

- finanzielle Führung im Jahreszyklus von Planung, Budgetierung, Controlling und Reporting, Kennziffern als Mittel der Führungspraxis;

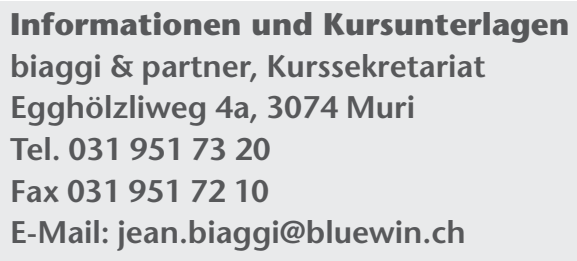

- DRG als Leistungsentschädigung;

- direkte Konsequenzen auf den Spitalbetrieb anhand erster Erfahrungen aus der Praxis;

- finanzgestützte Entscheide in besonderen Situationen.

\section{Zielpublikum}

Ärztinnen und Ärzte aller Fachgebiete in Kaderposition (Chefärzte / Leitende Ärzte / Oberärzte)

\section{Dozenten}

- Dr. rer. pol. Heinz Locher, Unternehmensberater, Bern / Dr. rer. pol. Kurt Aeberhard, Innopool AG, Schüpfen;

- Dr. med. Markus Trutmann, DRG-Experte, Zürich / Dr. med. Gallus Burri, Chefarzt, Kantonsspital Uri.

\section{Kursdatum}

6. und 7. November 2008.

\section{Kursort}

Kongress-Hotel Ramada, Solothurn.

\section{Kurskosten}

2 Kurstage inklusive Mittagessen, Getränke, Pausenverpflegung, Infrastruktur und Kursunterlagen: Fr. 1900.-.

\section{Anmeldung}

Bis 20. September 2008. 